\title{
A EVOLUCCÃO TECTONOTERMAL PROTEROZÓICA DO CRÁTON DO SÃo FRANCISCO, COM BASE EM INTERPRETAÇÕES GEOCRONOLÓGICAS K- Ar EM ROCHAS DO SEU EMBASAMENTO
}

\author{
W.Teixeira ${ }^{1} \&$ F.Canzian²
}

PALAVRAS-CHAVE: Cráton do São Francisco, geocronologia, evolução tectônica.

TEIXEIRA, W.; CANZIAN, F. (1994) A evoluçăo tectonotermal proterozóica do Cráton do São Francisco, com base em interpretaçöes geocronológicas K-Ar em rochas do seu embasamento. Bol.JG-USP, Sér.Cient., 25:61-80.

\section{RESUMO}

Mais de 400 dataçōes K-Ar compōem o banco de dados radiométricos do Cráton do Såo Francisco (CSF). A partir da análise das idades K-Ar em rochas da infraestrutura (cerca de $65 \%$ dos dados), e tendo em vista o quadro da evoluçato crustal estabelecido com base em dataçóes U-Pb, Rb-Sr, $\mathrm{Pb}-\mathrm{Pb}$ e Sm-Nd, é apresentada uma interpretaçāo acerca da história tectonotermal do CSF, durante o Proterozóico.

A análise da informaçăo é realizada por região geográfica (setores central, NE, NW, SW, meridional e leste), e com base nos padrōes de idade $\mathrm{K}-\mathrm{Ar}$ em micas e anfibólios. As interpretaç̋̃es são comparadas com o quadro evolutivo, tanto das rochas da infraestrutura como da supraestrutura do CSF, e levando em conta também o padrão geocronológico K-Ar nas faixas móveis adjacentes.

O registro de idades entre 2,1 e $1,8 \mathrm{Ga}$, na maior parte da infraestrutura indica 0 soerguimento gradativo do CSF que acompanhou a estabilizaçāo tectônica dos cinturōes Itabuna, Correntina-Guanambi e Mineiro, durante o Ciclo Transamazônico. As idades entre 1,72 e 1,65 Ga, registradas na extremidade nordeste do cinturăo Itabuna e no cinturăo Mineiro, săo interpretadas como um reflexo do soerguimento associado ao colapso extensional do rift Espinhaço, cuja origem se deu há $1,75 \mathrm{Ga}$. Os intervalos de idade $0,80 / 0,65 \mathrm{Ga}$ e $0,65 / 0,50 \mathrm{Ga}$, detectados nas bordas do CSF e no interior da provincia Paramirim, sảo interpretados como relacionados aos processos colisionais das faixas móveis marginais neoproterozóicas. Em especial, esta província parece representar uma zona reativada (deformaçåo, metamorfismo e rejuvenescimento isotópico), como reflexo da tectônica convergente das faixas Rio Preto e Araçuai em relação ao CSF.

A análise integrada da geocronologia K-Ar, aliada aos dados geológicos e estruturais, e ao cenário da evoluçäo crustal, sugere que o CSF manteve-se como unidade fisicamente integra durante o Neoproterozóico, embora as rochas da infraestrutura nas margens leste e sudeste e na provincia Paramirim tenham sido fortemente reativadas durante o Brasiliano.

\section{ABSTRACT}

The geochronologic data base for the São Francisco Craton (SFC) includes more

\footnotetext{
${ }^{1}$ Departamento de Geologia Geral, Instituto de Geociências/USP, São Paulo, Brasil.

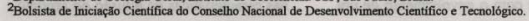


than $400 \mathrm{~K}$-Ar age determinations. The K-Ar ages on crystalline basement rocks characterize regional cooling patterns within the SFC, that permit definition of its tectonothermal history during the Proterozoic. This history is also substantiated by the crustal evolution postulated for the SFC and by the $\mathrm{U}-\mathrm{Pb}, \mathrm{Rb}-\mathrm{Sr}, \mathrm{Pb}-\mathrm{Pb}, \mathrm{Sm}-\mathrm{Nd}$ ) data including that of its adjacent Neoproterozoic fold belts.

Regional cooling of large domains of the SFC occurred mostly during the Transamazonian cycle as a result of progressive uplift accompanying the tectonic stability of the Itabuna, Correntina-Guanambi and Mineiro belts, around 2,1 - 1,8 Ga ago. The 1,72-1,65 Ga age pattern identified in sectors of the Itabuna (Salvador region) and Mineiro belts (west of Belo Horizonte) suggests a relationship with the geodynamics associated with the extensional collapse of the Espinhaço rift originated at ca. $1.75 \mathrm{Ga}$ ago. The $0,80 / 0,65 \mathrm{Ga}$ and $0,65 / 0,50 \mathrm{Ga}$ age intervals are characteristic for the basement rocks located at the borders of the SFC and in the Paramirim province. These patterns may have a tectonic link with the collision processes against the SFC, of the marginal Neoproterozoic belts. In special, the K-Ar resetting in the Paramirim province accompanied deformation and metamorphic overprint of the crystalline basement, probably in association with the collision of the Rio Preto and Araçuai belts.

As a whole, the $\mathrm{K}-\mathrm{Ar}$ age patterns coupled with the geologic and structural scenario and the crustal evolution of the SFC reveal it consists a forcland unit for the surrounding tectonics that took place in eastern Brazil, during the Neoproterozoic. Nevertheless, the basement rocks located in the southeast and east borders of the SFC and in the Paramirim province have been reactivated due to the Brasiliano cycle evolution marginal to the craton.

\section{INTRODUÇÃO}

O banco de dados geocronológicos e isotópicos do Cráton do São Francisco (CSF) e respectivo texto explicativo são uma das atuais prioridades do Centro de Pesquisas Geocronológicas (CPGeo) do Instituto de Geociências (IG), Universidade de São Paulo (USP). A conclusão deste projeto, através do levantamento dos dados $\mathrm{Rb}-\mathrm{Sr}$, $\mathrm{K}-\mathrm{Ar},{ }^{39} \mathrm{Ar}-{ }^{40} \mathrm{Ar}$, U-Pb, $\mathrm{Pb}-\mathrm{Pb}$ e $\mathrm{Sm}$ $\mathrm{Nd}$, deverá trazer à comunidade geológica uma importante fonte de consulta para os interessados na evolução préCambriana de um dos mais debatidos segmentos cratônicos da Plataforma Sul Americana.

O projeto já tem concluido o banco de dados K-Ar em rochas do embasamento do CSF o que permite avançar na interpretação acerca da sua história térmica proterozóica, tendo-se em conta a sua evolução crustal e o cenário tectônico estabelecido pelas faixas móveis brasilianas marginais ao cráton. $\mathrm{O}$ presente trabalho é produto de um programa de Iniciação Científica (Teixeira \& Silva, 1993) com o envolvimento de um graduando em Geologia (F. Canzian da Silva), sob os auspícios do Conselho Nacional de Desenvolvi-mento Cientifico e Tecnológico - CNPq (processo $\mathrm{n}^{\circ}$ 108.014/92-4; anos 93/94). O projeto foi motivado pela publicação pioneira do Mapa Geocronológico do estado da Bahia (Mascarenhas \& Garcia, 1989), o qual é uma referência de consulta fundamental aos interessados na Geocronologia em geral.

A compilação de datações $\mathrm{K}-\mathrm{Ar}$ envolveu as rochas do embasamento e intrusivas, tanto no CSF como nas faixas móveis marginais, próximo ao limite cratônico. Além disso, foram elaborados mapas temáticos regionais (com a localização das idades) e locais (com os padrôes geocronológicos delineados).

\section{FUNDAMENTOS GEOCRONOLÓ- GICOS E CRITÉRIOS DE ANÁLI- SE ADOTADOS}

As interpretações geocronológicas regionais e locais foram fundamentadas nas características de difusão do argônio 
em micas e anfibólios de rochas metamórficas de médio a alto grau. As temperaturas de bloqueio para o argônio nestes minerais acham-se razoavelmente estabelecidas em função de parâmetros próprios de difusão, taxas de resfriamento e raio efetivo de difusão de argônio desses minerais (e.g., Hanes, 1991). No caso específico da biotita, muscovita e hornblenda, as temperaturas criticas para a difusão de argônio são da ordem, respectivamente, de $300 \pm 50^{\circ} \mathrm{C}, 350 \pm 50^{\circ} \mathrm{C}$ e $500 \pm 50^{\circ} \mathrm{C}$, acima das quais não há acúmulo de argônio radiogênico (e.g., Harrison, 1981; Harrison et al., 1985; Dalrymple \& Lanphere, 1969). Especialmente as micas e anfibólios de terrenos metamórficos são utilizados para o estabelecimento da história termal de segmentos continentais, uma vez que fornecem uma resposta inerente ao argônio retido e acumulado, conforme as respectivas temperaturas de bloqueio. Os feldspatos, todavia, não são frequientemente utilizá-veis neste tipo de interpretação porque, além de exibirem temperaturas de bloqueio variáveis, em função de sua composição química (presença de pertitas por exemplo), a difusão de argônio inicia-se em temperaturas variáveis, inferiores a $230^{\circ} \mathrm{C}$ (e.g. Faure, 1986; Hanes, 1991).

No presente trabalho, a interpretaçăo das idades teve como critério adicional a homogeneidade obtida no padrão de resfriamento $\mathrm{K}$-Ar (concentraçōes de idade em determinados períodos de tempo) e sua coerência ao longo de um dado segmento continental. O comportamento das idades, tanto no substrato do CSF como o das faixas móveis brasilianas adjacentes, é interpretado como devido ou a soerguimento crustal, ocorrido posteriormente ao principal evento metamórfico regional, ou relacionado ao processo colisional das mesmas. $O$ soerguimento e consequente resfriamento dos terrenos metamórficos, por sua vez, são considerados como dependentes das isotermas de temperaturas de bloqueio caracteristicas das micas e anfibólios, similarmente ao exemplificado para as rochas do Escudo Canadense (Stockwell, 1982). A estratégia do trabalho visou também minimizar a inclusão no banco de dados de idades anômalas, decorrentes de eventuais processos de incorporação ou perda de argônio nos minerais datados.

Finalmente, a subdivisão temporal dos conjuntos de idade a serem utilizados no texto, foi fundamentada nas concepções utilizadas corriqueiramente na literatura brasileira quanto à estabilização tectônica do Ciclo Transamazônico (1.9-1.8 Ga) representar a passagem entre o Paleoproterozóico e o Mesoproterozóico, e ao início do Neoproterozóico ser representado pelos eventos tectônicos no intervalo de tempo $1.0-0.9 \mathrm{Ga}$. O presente trabalho ainda adota a idade de $2.5 \mathrm{Ga}$ como representativa da transição tectônica entre os Eons Arqueano e Proterozóico (Brito Neves et al., 1990).

\section{BANCO DE DADOS K-Ar}

A compilação dos dados analíticos $\mathrm{K}$-Ar abrangeu os diferentes materiais datados (micas, anfibólios, rocha total e feldspato), a partir de publicações, dissertaçōes de mestrado e teses de doutorado, além de dados inéditos existentes no acervo do CPGeo. A listagem de dados incluíu o número de campo das amostras, a rocha datada, os dados laboratoriais completos e a respectiva fonte bibliográfica. Além disso, o trabalho recuperou a localização geográfica das dataçōes (latitude e longitude), esta representada em uma base simplificada do Mapa Geológico do Brasil (Schobbenhaus et al., 1984). Este esboço (Fig. 1), elaborado inicialmente em papel vegetal, foi posteriomente digitalizado com o emprego do software Autocad-12.

Os trabalhos de digitalização foram realizados no Centro de Processa- 


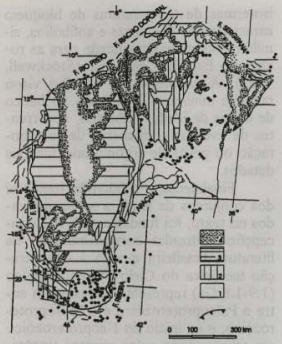

Figura 1- Mapa da distribuição geográfica das dataçōes no CSF e áreas adjacentes. Base geológica adaptada do Mapa Geológico do Brasil (Schobbenhaus et al., 1984). I = Infraestrutura e supraestrutura do CSF, e embasamento da área adjacente ao cráton envolvido nos processos tectónicos das faixas móveis brasilianas, 2 = Unidades mesoproterozóicas. $3=$ Unidades neoproterozóicas. 4 = Coberturas fanerozóicas. 5 = Limite do cráton segundo Alkmim et al. (1993), estando também representados os principais empurrōes (dentes). Os pontos indicam a localização das dataçốes K-Ar.

mento de Dados do IG-USP, com emprego de um micro-computador AT486, mesa digitalizadora e plotter. A opção pelo programa Autocad deveu-se ao fato deste soffware permitir a confecção rápida de mapas em diferentes escalas, facilitando, assim, a gradativa incorporação dos dados compilados, em compatibilidade com a atualização do desenho. Além disso, outra qualidade da edição Autocad é a armazenagem dos arquivos utilizando apenas disquetes.

$\mathrm{Na}$ Figura 1 acham-se representadas fundamentalmente a infraestrutura do CSF (que inclui as supracrustais mais velhas que $1,8 \mathrm{Ga}$ ) e o embasamento en- volvido nos processos de deformação e metamorfismo do Ciclo Brasiliano (dominio das faixas móveis), as unidades Meso e Neoproterozóicas, e as coberturas sedimentares mais recentes (idade fanerozóica). Esta simplificação visou dar maior clareza gráfica à distribuição espacial do acervo de datações. No entanto, nas Figuras 3 a 7 , as sequuências supracrustais do Arqueano e/ou Paleoproterozóico foram também representadas, tendo em vista que a escala adotada é mais favorável à distribuição geográfica dos dados geocronológicos em compatibilidade com o contexto geológico. Estes mapas de setores especificos objetivaram delinear os padrōes de resfriamento, representados por meio de simbologia dos materiais datados e intervalos de idade considerados como caracteristicos, possivelmente decorrentes de processo(s) geológico(s) peculiar destes setores.

O acervo de datações (Fig. 1) restringiu-se às rochas de infraestrutura, $\mathrm{u}$ ma vez que estas produziram uma resposta mais característica do sistema KAr em termos da história térmica regional. Os dados compilados referem-se basicamente ao dominio do CSF, porém incluem também aqueles da infraestrutura de setores adjacentes nas faixas móveis Sergipana, Araçuai, Ribeira e Rio Preto, tendo em vista as comparações pretendidas. $\mathbf{O}$ acervo deixou de incluir, nesta etapa, o conjunto de dataçōes K-Ar da borda oeste do CSF (e.g., Hasui et al., 1980), devido ao fato da extensa cobertura cratônica năo contar com datações que permitissem formar um quadro comparativo entre o domínio do antepaís e a faixa Brasilia. Pode-se notar, pela distribuição geográfica das datações na Figura 1, que ocorre uma maior concentração na parte sul da área investigada, o que permitiu um relativo melhor detalhamento das interpretaçōes.

Finalmente, o acervo completo do 
banco de dados, incluindo as rochas da infraestrutura, supraestrutura e intrusivas, encontra-se à disposição dos interessados ${ }^{(*)}$.

\section{PROVINCIAS GEOCRONOLÓGI- CAS DO CRÁTON DO SÃO FRAN- $\mathrm{CISCO}$}

O desenvolvimento crustal do CSF (Almeida, 1977) iniciou-se no Arqueano, com recorrência de processos tectonomagmáticos durante o Paleoproterozóico. O caráter policíclico da evolução está ilustrado pelo conjunto de dados radiométricos ( $\mathrm{Rb}-\mathrm{Sr}, \mathrm{Sm}-\mathrm{Nd}$, U-Pb, $\mathrm{Pb}-\mathrm{Pb},{ }^{40} \mathrm{Ar}-{ }^{39} \mathrm{Ar}$ e $\mathrm{K}-\mathrm{Ar}$ ) nos terrenos de infraestrutura (principalmente), supraestrutura, intrusivas plutônicas e rochas vulcânicas (e.g., Brito Neves et al., 1980; Cordani \& Brito Neves, 1982; Mascarenhas \& Garcia, 1989; Teixeira \& Figueiredo, 1991, Teixeira, 1992). A compartimentação geocronológico/geológica e o cenário paleotectônico podem ser ilustrados através da individualização de províncias arqueanas e proterozóicas (Teixeira, 1992, 1993), expostas tanto na porção setentrional como meridional do CSF (Fig. 2). Trata-se de domínios geográficos extensos, com comportamento geocronológico coerente entre os vários métodos de datação aplicados em suas rochas, em decorrência de uma de-

(") pesquisadores interessados no banco de dados devem enviar 2 disquetes $\left(3,5^{\prime \prime}\right)$ para o primeiro autor do trabalho, acompanhando carta com solicitaçāo para o uso das informaçōes geocronológicas. Para maior facilidade na con-sulta dos dados analíticos no arquivo de "plottagem", estes acham-se tabelados em número de ordem crescente, com a correspondente localizaçado geográfica representada no mapa geológico simplificado da área investigada. O uso do acervo de dados está condicionado à mençāo clara da fonte de consulta $c$ autores do acervo $e$ instituiçōes patrocinadoras do projeto (IG-USP e CNPq). terminada etapa da evolução crustal. Esta concepção corresponde a uma provincia geocronológica, a qual acha-se fundamentada geologicamente por processos plutônicos e vulcânicos e sedimentares, além de feições estruturais e metamórficas características do conjunto de unidades estratigráficas expostas.

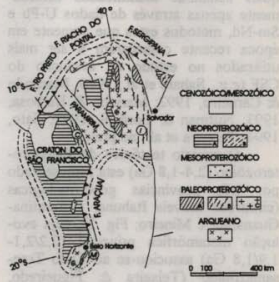

Figura 2 - O Cráton do São Francisco e suas provincias geocronológicas. As Provincias Arqueanas (setentrional e meridional) acham-se margeadas pelos Cinturões Paleoproterozóicos: I (Cinturâo Itabuna), W (Cinturã̃o CorrentinaGuanambi) e M (Cinturăo Mineiro). Limite do cráton segundo Alkmim et al. (1993).

O conteúdo geocronológico da área investigada, referente ao Arqueano, sugere a existência de duas províncias, com evolução tectonomagmática no período de tempo $3,4-2,7 / 2,6 \mathrm{Ga}$ (e.g. Nutman \& Cordani, 1993; Teixeira, 1993; Teixeira et al., no prelo). Litologicamente, estas provincias acham-se representadas por associações do tipo granito-greenstone e terrenos metamórficos de médio a alto grau, variavelmente submetidos a migmatização e anatexia. Aparentemente, o intervalo de tempo entre 2,8-2,6 Ga foi o de maior importância para o espessamento da crosta continental arqueana, conforme sugerem 
a maior frequência de idades neste intervalo e a ampla distribuição geográfica das rochas com este padrẫo radiométrico no interior do CSF. Todavia, as características policíclicas da evolução, envolvendo inclusive adiçōes juvenis, possivelmente obscureceram grande parte dos registros isotópicos primários, os quais acham-se identificados escassamente apenas através de dados U-Pb e $\mathrm{Sm}-\mathrm{Nd}$, métodos estes que somente em época recente começaram a ser mais utilizados no estudo da evolução do CSF (e.g., Sabaté et al,, 1990; Machado \& Carneiro, 1992; Marinho \& Barbosa, 1993; Nutman \& Cordani, 1993; Sato, 1994; Teixeira et al., no prelo)

O cenário tectônico do Paleoproterozóico (2,4-1,8 Ga) está representado por três provincias geocronológicas (cinturões móveis Itabuna, CorrentinaGuanambi e Mineiro; Fig. 2), cuja evolução metamórfica principal (2,2/2,11,9/1,8 Ga) associou-se ao Ciclo Transamazônico (Teixeira \& Figueiredo, 1991). Tal evolução foi responsável pelo espessamento adicional do proto-cráton através de colisões entre blocos continentais, gerando encurtamento crustal, além de granitizações e migmatizações (e.g., Brito Neves et al, 1980; Figueiredo, 1989; Sabaté et al., 1990). A tectônica peculiar destes cinturões, com o soerguimento dos blocos de embasamento e formação de zonas de cisalhamento extensionais, sugere um desenvolvimento adjacente às províncias arqueanas (e.g., Cordani \& Brito Neves, 1982; Chemale Jr. et al., 1991). Em consequência, as margens do continente primitivo foram retrabalhadas diferencialmente, conforme evidenciado pela assinatura crustal dos isotópos de $\mathrm{Sr}, \mathrm{Nd}$ e $\mathrm{Pb}$ em gnaisses de médio a alto grau metamórfico e rochas plutônicas e vulcânicas destes cinturões móveis (e.g., Brito Neves et al., 1980; Cordani \& Brito Neves, 1982; Wilson, 1987; Teixeira et al., 1987; Sabaté et al., 1990; Teixeira
\& Figueiredo, 1991; Teixeira, 1993). A evolução dos cinturốes Itabuna, Correntina-Guanambi e Mineiro foi também acompanhada por intrusōes de corpos graníticos e alcalinos e enxames de diques básicos (intrusivos inclusive no antepais arqueano), antecedendo o soerguimento generalizado da extensa massa continental. Este último episódio associou-se à etapa de estabilização tectônica do Ciclo Transamazônico, por volta de 1,9-1,8 Ga (e.g., Teixeira, 1985; 1992).

A compartimentação tectônica do CSF inclui também uma província geocronológica com idades no intervalo de tempo 1,79-1,70 Ga. Esta província está representada geologicamente pelo sistema Espinhaço - uma zona de grabens e bacias intracratônicas instalada ao longo do eixo NNW-SSE do CSF, cujo início se deu através de contribuições vulcânicas ácidas, datadas pelo método $\mathrm{U}-\mathrm{Pb}$ em zircões (Brito Neves et al., 1979; Machado et al., 1989; Schobbenhaus et al., 1994; Babinski et al., 1994). Eventos plutônicos com expressão regional aliados a metamorfismo acham-se também associados à evolução desta província. E o caso do vale do Paramirim (Fig. 2), onde ocorrem diversas rochas ortognáissicas (e.g., Complexo Lagoa Real) e granitóides, contemporâneas em idade à implantação do sistema Espinhaço, conforme revelam dataçōes U-Pb em zircão e titanita (Turpin et al, 1988; Pimentel et al., 1994). A assinatura isotópica de $\mathrm{Sr}$ e $\mathrm{Pb}$ destas rochas graníticas intrusivas, a exemplo do Granito São Timóteo, é tipicamente crustal com altos valores de razõe. iniciais e $\mu_{1}$ (e.g., Cordani et al., 1992).

Aparentemente, a dinâmica do Mesoproterozóico ter-se-ia iniciado através de uma tectônica extensional, sinalizada por vulcanismo e plutonismo ácido e básico associados à ruptura abortada do então recém-consolidado extenso continente transamazônico (e.g., 
Teixeira, 1993; Alkmim et al., 1993). Esta evolução foi acompanhada por uma parcial rehomogeneização isotopica $\mathrm{Rb}$ Sr das rochas supracrustais e metavulcânicas do sistema Espinhaço (e.g., Brito Neves et al., 1980), como resposta de um processo de inversão de riftes antes nucleados, aliada a processos tectônicos mais jovens.

O caráter latente e prolongado de instabilidade tectônica nesta zona axial do CSF, ilustrado pelo rejuvenescimento das idades isotópicas ( $\mathrm{Rb}-\mathrm{Sr}$ e K-Ar), tanto das rochas de infraestrutura como das supracrustais do sistema Espinhaço, está aparentemente relacionado à convergência tectônica dos cinturões móveis brasilianos marginais ao CSF (e.g., Brito Neves et al., 1980; Cordani et al., 1985, 1992; Teixeira, 1992; Trompette, 1994). Tal hipótese apoia-se na correlaçáo estrutural das feições do Grupo Bambui com as observadas no sistema Espinhaço meridional e setentrional, Chapada Diamantina e também no vale do Paramirim (e.g., Chemale Jr. et al., 1992; Alkmim et al,, 1993).

Cabe também observar a existência de diversas atividades anorogênicas ao longo do sistema Espinhaço (enxames de diques máficos e complexos alcalinos), com idades nos intervalos de tempo $1,9-1,8 \mathrm{Ga} ; 1,7-1,3 \mathrm{Ga} ; 1,1-1,0$ $\mathrm{Ga} ; 0,9 \mathrm{Ga}$ e $0,7-0,6 \mathrm{Ga}$ (e.g., Cordani et al., 1974; Lima et al., 1981; Teixeira, 1985; Renne et al., 1990; Heaman, 1991; Bastos Leal et al., 1994; Bastos Leal et al., no prelo), as quais revelam o caráter episódico dos esforços distensivos que atuaram no CSF. Um dos exemplos mais notáveis do fraturamento é o enxame de diques máficos de IllhéusOlivença de direção E-W, exposto ao longo da costa atlântica da Bahia, e que se encontra datado em 1,1-1,0 Ga pelo método ${ }^{40} \mathrm{Ar}-{ }^{39} \mathrm{Ar}$ (Renne et al., 1990).

No Neoproterozóico o CSF consolidou-se, vindo a constituir o antepais dos processos tectônicos brasilianos a- tuantes nas faixas móveis marginais. Nesta era a porção ocidental do antepaís foi recoberta por depósitos plataformais de caráter clástico-químico (Grupo Bambuí), afora outros depósitos menos extensos (Grupos Una, Rio Pardo). Particularmente o Grupo Bambuí apresentase intensamente deformado próximo às bordas do CSF (e.g., Almeida, 1977). Recentes estudos estruturais nas exposiçōes meridionais do CSF revisaram o conceito deformacional do Grupo Bambui, uma vez que revelaram que extensas partes da cobertura, inclusive em pleno interior cratônico (ver acima), acham-se tectonizadas, com falhamentos e dobras gerados em associação com o desenvolvimento dos cinturões brasilianos marginais Araçuai, Brasília e Rio Preto (e.g., Alkmim et al., 1993). Apenas uma zona central do Grupo Bambui mostrase imune à deformação, possivelmente condicionada por altos estruturais prébrasilianos que controlaram não somente a deposição sedimentar como influenciaram na inversão da bacia.

Tendo em vista o exposto acima quanto à complexidade do quadro geológico, torna-se obrigatório que a interpretação das idades $\mathrm{K}$-Ar tenha por base uma análise comparativa dos padrões geocronológicos obtidos por outros métodos radiométricos (U-Pb, Sm-Nd, Rb$\mathrm{Sr}, \mathrm{Pb}-\mathrm{Pb}$ ), de modo a substanciar o cenário tectônico estabelecido pelas provincias geocronológicas do CSF, bem como pela geodinâmica convergente das faixas móveis brasilianas marginais.

\section{DISCUSSÃO DOS DADOS}

Os mapas geocronológicos (Figs. 3 a 7) permitem verificar a grande variação das idades aparentes K-Ar em função da distribuição geográfica, ilustrando a complexidade da evolução crustal. Desta forma, em prol da confiança nas inferências geológicas a serem propostas, as interpretaçôes geocronológicas 


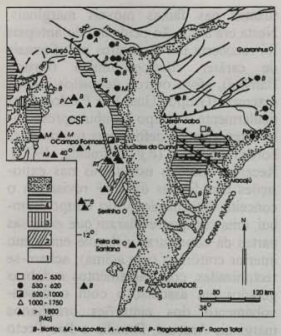

Figura 3 - Padrăo geocronológico K-Ar do setor nordeste da área investigada. Legenda conforme Figura 1. FS = Faixa Sergipana. FRP $=$ Faixa Rio Preto. Linha tracejada representa o limite do CSF (Cráton do Săo Francisco), segundo Alkmim et al. (1993).

K-Ar terão em conta apenas os principais padrões caracterizados, os quais aqui serão considerados como representativos em termos de processos tectôni$\cos$.

A seguir discutem-se detalhadamente os dados geocronológicos nos diferentes setores da área investigada.

\section{Setor Nordeste}

Os terrenos granulíticos da costa atlântica na região de Salvador pertencem ao cinturão Itabuna, cujo evento metamórfico principal ocorreu no periodo entre 2,20-2,00 Ga (e.g., Figueiredo, 1989; Teixeira \& Figueiredo, 1991). Estes terrenos exibem idades KAr em micas entre $1,72-1.65 \mathrm{Ga}$, porém também registrando valores mais jovens de 1,54 Ga (Fig. 3). Este intervalo de idades distingue-se do padrão de resfriamento típico do Ciclo Transamazônico,

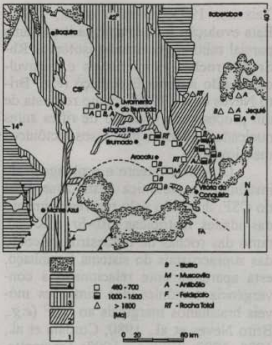

Figura 4 - Padrão geocronológico $\mathrm{K}$-Ar do setor central-norte. Legenda conforme Figura 1. FA = Faixa Araçuai, Linha tracejada representa o limite do CSF (Cráton do São Francisco), segundo Alkmim et al., (1993).

observado nos setores mais a oeste do cinturão Itabuna, onde as idades K-Ar e ${ }^{40} \mathrm{Ar}-{ }^{39} \mathrm{Ar}$ situam-se no intervalo 2,10 $1,80 \mathrm{Ga}$ (e.g., Cordani, 1973; Lima et al., 1981; Mascarenhas \& Garcia, 1989; Sletten, 1989; Renne et al., 1990).

A comparação do padrão 1,72 $1,65 \mathrm{Ga}$ com a evolução contemporânea da provincia Espinhaço parece possivel, sendo coerente com o contexto geodinâmico do proto-CSF no início do Mesoproterozóico. Deste modo, é provável que o padrão de idades acima seja um efeito do soerguimento das áreas adjacentes (e.g., região de Salvador) à esta zona de grabens, relacionado ao colapso extensional do proto-cráton. Em consequêencia, ocorreria o fechamento mais tardio do sistema K-Ar, após a estabilização regional do Ciclo Transamazônico.

Cabe também registrar o brusco contraste geocronológico entre o domi- 


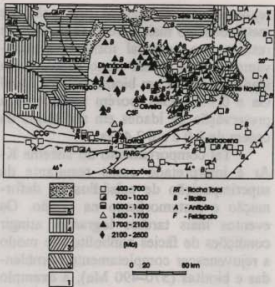

Figura 5 - Padrão geocronológico K-Ar do setor meridional da área investigada. Legenda conforme Figura 1. CCG = Complexo Campos Gerais; $F A R G=$ Faixa Alto Rio Grande. Linha tracejada representa o limite do CSF (Cráton do São Francisco), adaptado de Alkmim et al. (1993) e Valeriano (1992).

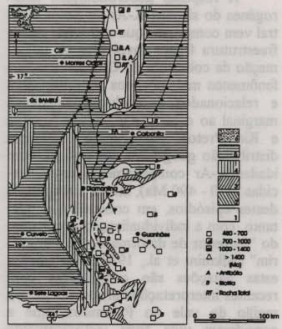

Figura 6 - Padrão geocronológico K-Ar do setor leste da área investigada. Legenda conforme Figura 1. FA = Faixa Araçuai. Linha tracejada representa o limite do CSF (Cráton do São Francisco), segundo Alkmim et al., (1993).

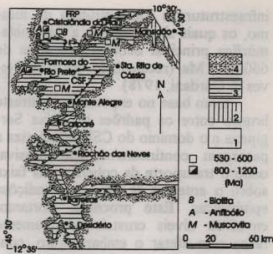

Figura 7- Padrão geocronológico K-Ar do setor noroeste da área investigada. Legenda conforme Figura 1. FRP = Faixa Rio Preto. Linha tra. cejada representa o limite do CSF (Cráton do Så̃o Francisco), segundo Alkmim et al., (1993).

nio acima e o do cinturão Sergipano (Fig. 3). Neste cinturão as rochas do substrato e granitóides exibem idades KAr concentradas entre $620-530 \mathrm{Ma}$ (muscovitas e biotitas), padrão este que pode ser acompanhado ao longo de toda a frente da faixa móvel. Ao se detalhar a análise deste comportamento geocronológico, verifica-se que as rochas graniticas e afins da faixa dobrada possuem idades $\mathrm{K}-\mathrm{Ar}$ da ordem de $590 \mathrm{Ma}$. Isto caracteriza o estágio tarditectônico na faixa, ao passo que as idades mais jovens, em torno de $530 \mathrm{Ma}$, referir-seiam ao soerguimento regional. Há ainda uma idade anômala (1710 Ma), registrada no domo de Itabaiana (ao sul de Aracajú). Trata-se de uma idade em biotita, aqui interpretada como híbrida, em decorrência do possivel rejuvenescimento parcial da rocha datada, situada na zona marginal do antepais. De todo modo, a concentração das idades entre 620 - $530 \mathrm{Ma}$ está associada à evolução tectonomagmática brasiliana do cinturão Sergipano (e.g., Almeida, 1977; Brito Neves \& Cordani, 1978), sendo coerente com dados $\mathrm{Rb}-\mathrm{Sr}$ isocrônicos na 
infraestrutura e supraestrutura do mes$\mathrm{mo}$, os quais sinalizam que a fase metamórfica principal ocorreu por volta de 660-650 Ma (recalculado de Brito Neves \& Cordani, 1978).

Com base no exposto, o contraste brusco entre os padróes da Faixa Sergipana e o dominio do CSF caracteriza a passagem continente/margem passiva, onde o transporte da cobertura da faixa sobre o antepais se deu em condições epitérmicas. Este processo, portanto, envolveu níveis crustais relativamente rasos sem afetar o embasamento, conforme ilustrado no presente caso pelas idades $\mathrm{K}-\mathrm{Ar}$ em micas e anfibólios entre 2,1-1,82 Ga (porções setentrionais do cinturão Itabuna), típicas do resfriamento do Ciclo Transamazônico A única exceção, uma idade aparente da ordem de $770 \mathrm{Ma}$, situa-se na extremidade ocidental cratônica a nordeste de Campo Formoso, muito próximo à zona frontal da Faixa Sergipana (Fig. 3). Esta idade pode resultar de fenômenos de reequilibrio isotópico influenciados pela inversão tectônica associada aos cavalgamentos e empurrões da faixa.

\section{Setor Central}

Idades K-Ar aparentes entre 1,75 $1,00 \mathrm{Ga}$ ilustram, de maneira geral, a superimposição de processos tectonotermais em determinados setores do CSF. No Setor Central, o comportamento acha-se tipificado nas regiōes arqueanas de Boquira-Brumado-Aracatu (vale do Paramirim; Figs. 2 e 4), e também nas extremidades dos terrenos granuliti$\cos$ Jequié, onde se constata um rejuvenescimento progressivo nas idades aparentes $\mathrm{K}-\mathrm{Ar}$ em biotitas no sentido NESW, já anteriormente detectado por Cordani et al. (1985). No lado nordeste desta região (Complexo Jequié), as idades em biotitas e anfibólios distribuemse predominantemente entre 2,1 e 1,8 $\mathrm{Ga}$, mas já ocorrendo uma idade de 1,5 $\mathrm{Ga}$ (em anfibólio), em decorrência de rejuvenescimento parcial por ação de metamorfismo mais jovem. $O$ padrão de resfriamento regional torna-se gradativamente mais jovem rumo a SW (com idades variáveis em biotita entre 1,5-0.9 Ga e $0,7-0,5 \mathrm{Ga}$ ), porém ainda com a preservação de idades em anfibólios da ordem de 2,0 e até $2,4 \mathrm{Ga}$.

Tal comportamento do sistema KAr é interpretado como resultante da superimposição de episódios de deformação e metamorfismo na região. Os eventos mais tardios lograram atingir condiçōes de fácies anfibolito, de modo a rejuvenescer completamente hornblendas e biotitas (570-490 Ma), a exemplo das datações compiladas na regiāo a norte de Lagoa Real (Fig. 4). Este rejuvenescimento encontra-se também registrado nos metassedimentos quartzo-xistosos do Supergrupo Espinhaço através das idades K-Ar entre 620 e 450 Ma (Távora et al., 1967; Cordani, 1973).

A resposta geocronológica heterogênea do sistema K-Ar no Setor Central vem comprovar que as rochas da infraestrutura foram envolvidas na deformação da cobertura do CSF associada a fenômenos metamórficos superimpostos e relacionados à evolução brasiliana marginal ao cráton (e.g., faixas Araçuai e Rio Preto). Além disso, a ampla distribuiçâa geográfica das rochas, com idades K-Ar completamente rejuvenescidas ( $570-490 \mathrm{Ma})$, ilustra a amplitude destes episódios, em consonância, portanto, com a individualização do chamado "corredor de deformação do Paramirim" (Alkmim et al., 1993). Em adição, estas datações são consistentes com recentes interpretações propostas para a região do vale do Paramirim, que a consideram uma zona tectonicamente instável durante o Proterozóico, com base em feições geológicas, metamórficas e estruturais no embasamento e sua cobertura (e.g., Dominguez, 1993; Chemale Jr. et al., 1992; Trompette et al,, 


\section{3).}

Em síntese, o padrão $\mathrm{K}-\mathrm{Ar}$ no Setor Central ratifica a hipótese aventada por Alkmim et al. (1993) quanto à associação da mesma, em termos geodinâmicos, com os processos deformacionais contemporâneos nos cinturões colisionais Rio Preto e Araçuai, às margens do CSF. Este último cinturão, de outra parte, ter-se-ia instalado parcialmente sobre uma herança tectônica do sistema Mesoproterozóico Espinhaço (Trompette, 1989). O metamorfismo e deformação, que aumentam progressivamente em direção ao centro do cinturão (e.g., Almeida, 1977; Pedrosa Soares et al., 1992; 1993), acham-se datados em 680 630 Ma (Cordani, 1973; Sá, 1977; Siga Jr., 1986; Litwinski, 1986). Este padrão acha-se bem refletido através das idades $\mathrm{Rb}-\mathrm{Sr}$ (idades mais jovens que $650 \mathrm{Ma}$ ) nas rochas mesozonais do alto curso do rio Jequitinhonha, por exemplo (e.g., Cordani, 1973; Siga Jr. et al. 1987; Mascarenhas \& Garcia, 1989). Segundo Trompette et al. (1993), a deformação no antepais, associada à colisão Araçuaí, acomodou-se por meio de dobramentos e falhamentos, ao longo do vale do Paramirim. Este processo, na concepção destes autores, culminaria com a ruptura do CSF no Ciclo Brasiliano.

O cenário deformacional da bacia Rio Pardo (Karmann, 1987), situado na margem do CSF, também é coerente com o comportamento geral de gradativa menor intensidade das deformações da faixa móvel rumo ao interior do antepaís. Estruturalmente, este quadro está detectado nas rochas supracrustais e nas formações neoproterozóicas da bacia pela variação na intensidade da deformação de SSW para NNE, e também através do rejuvenescimento isotópico com idades no intervalo de tempo 540-480 Ma (Cordani, 1973; recalculado de Lima et al., 1981). A história tectônica do antepais foi ainda acompanhada pela reativação de zonas de falhas, com geração de atividades igneas básicas e alcalinas anorogênicas com cerca de $680 \mathrm{Ma}$ (e.g., Cordani, 1973; Lima et al., 1981; Cordani et al., 1974), como resposta ao encurtamento crustal gerado pela colisão Araçuaí (Silva et al., 1993).

\section{Setor Meridional}

Padrōes geocronológicos compativeis com o Mesoproterozóico (1,43 $\mathrm{Ga}, 1,28-1,18 \mathrm{Ga}, 1,13-0,90 \mathrm{Ga})$, em micas, anfibólios e rocha total, acham-se delineados para a infraestrutura (autóctone) do Cráton, em sua extremidade sudoeste (Fig. 5). Esta constatação e a existência de enxames de diques anorogênicos de diferentes idades proterozóicas identificados em diversos tratos do CSF (e.g., Teixeira, 1992) sugere uma grande extensão geográfica para os processos de reativação tectônica durante este intervalo de tempo.

$\mathrm{Na}$ extremidade sudoeste do Setor Meridional as rochas de supraestrutura do Grupo Canastra (região de Cássia para sudeste) fornecem idades $\mathrm{K}$ - $\mathrm{Ar}$ em micas sistematicamente do Neoproterozóico $(0,73-0,56 \mathrm{Ga})$. Este padrão é muito mais jovem do que as idades $\mathrm{K}$-Ar obtidas para as rochas do embasamento policíclico alótone e autóctone na região a oeste de Lavras (Fig. 5), incluindo as rochas do Complexo Campos Gerais. Neste caso especifico, apesar do embasamento mostrar-se envolvido pela tectônica alóctone da nappe Araxá-Canastra, esta se deu em regime de baixa temperatura e sem o aporte de fluidos. Tais condições permitiram a preservação nas estruturas "duplex" das idades K-Ar entre 1,98 e $2,25 \mathrm{Ga}$ (e.g., Valeriano, 1992). Já no Complexo Campos Gerais, as idades aparentes situam-se nos intervalos $1,50-1,30 \mathrm{Ga}$ e $1,18-0,91 \mathrm{Ga}$ (e.g., Teixeira et al., 1989; Valeriano, 1992), talvez demonstrando a influência hibrida da herança estrutural da área e da tectônica brasiliana da Faixa Alto Rio 
Grande, marginal ao CSF.

Em nivel regional, as rochas do embasamento no Setor Meridional do CSF exibem um cenário $\mathrm{K}-\mathrm{Ar}$ ainda mais complexo. Na extremidade oriental, próximo ao contato com a cobertura Bambuí, as datações em anfibólios e biotitas acusam o seu resfriamento ao final do Ciclo Transamazônico, indicando um soerguimento continental contemporâneo e reflexo da estabilização tectônica do Cinturão Mineiro (Teixeira, 1985). Rumo a leste, no entanto, as idades aparentes em biotita mostram-se rejuvenescidas $(1,10-0,90 \mathrm{Ga} ; 0,90-0,70 \mathrm{Ga})$, como, por exemplo, no Complexo Bonfim e adjacências (Carneiro, 1992). Estas idades parecem refletir episódios tectônicos de média intensidade superimpostos na infraestrutura, associados às etapas tardias da imposição deformacional sobre o sistema Espinhaço e/ou aos eventos brasilianos à margem do antepais. Esta última hipótese é reforçada pelo rejuvenescimento completo do sistema $\mathrm{K}-\mathrm{Ar}$ do embasamento arqueano (retrabalhado no Ciclo Transamazônico pelo Cinturão Mineiro) em grande parte do Quadrilátero Ferrifero e nas suas extensões orientais, onde essas idades em micas concentram-se no tempo entre 0,65 e $0,45 \mathrm{Ga}$ (e.g., Hertz, 1970; Machado Filho et al, 1983; Teixeira, 1985; Teixeira et al., 1987), num padrão de resfriamento análogo ao das extremidades meridionais da Faixa Araçuai. Aplica-se aqui, portanto, uma interpretação semelhante àquela aventada anteriormente para o Setor Central, ou seja, do envolvimento do embasamento através da reativação de estruturas antigas, em condições de ambiência "quente", como reflexo da tectônica brasiliana marginal ao CSF, de tal forma a rejuvenescer completamente o sistema K-Ar.

Finalmente, é importante acrescentar que a interpretação acima coadunase com o cenário tectônico atualmente estabelecido para a porção meridional do CSF (e.g., Marshak et al., 1992; Chemale Jr. et al., 1991, 1992), em que os processos brasilianos causaram deformaçōes e falhamentos no Grupo Bambui, conforme anteriormente mencionado.

\section{Setor Leste}

A extremidade oriental do CSF (Fig. 6) mostra um comportamento KAr análogo ao da borda leste do Quadrilátero Ferrififero (Fig. 5), discutido acima. No âmbito da faixa móvel brasiliana Araçuai (regiões de Guanhães e Carbonita) constata-se um rejuvenescimento completo das idades em micas, concentradas entre 700 e $400 \mathrm{Ma}$ (e.g., Siga Jr., 1986; Teixeira et al., 1990). Especialmente no domínio mesozonal da faixa, os dados $\mathrm{K}$-Ar concentram-se no intervalo $540-480 \mathrm{Ma}$, ilustrando o período de resfriamento regional (Siga Jr. et al., 1987). Rumo a oeste, apesar da tectônica brasiliana, tanto em micas como em anfibólios, observam-se idades gradativamente mais antigas (intervalos $1,00-0,70$ e 1,40-1,00 Ga). Este fato demonstra que a porção mesozonal da Faixa Araçuai permaneceu aquecida por mais tempo, relativamente à porção epizonal.

$\mathrm{Na}$ janela tectônica de ItacambiraBarrocão (a leste de Montes Claros), onde afloram unidades gnáissico-migmatiticas arqueanas e transamazônicas, as idades $\mathrm{K}-\mathrm{Ar}$ em micas e rochas totais apresentam um padrão heterogêneo (Fig. 6), típico de terrenos policlíclicos. As idades variam entre $570-950 \mathrm{Ma}$, com um registro de $1,95 \mathrm{Ga}$ (Siga Jr. et al., 1987). Este conjunto de idades é interpretado como afetado pela tectônica brasiliana imposta ao setor, porém ainda preservando parcialmente a memória termal da evolução mais antiga.

Em sintese, o comportamento regional do sistema $\mathrm{K}-\mathrm{Ar}$, com valores gradativamente mais antigos em direção a oeste, parece configurar um padrão de 
resfriamento influenciado pela herança termal do antepaís anterior a do Ciclo Brasiliano.

\section{Setor Noroeste}

$\mathrm{Na}$ extremidade NW do CSF, similarmente à sua porção SW, a crosta transamazônica foi afetada por processos tectonotermais do Meso e Neoproterozóico (Fig. 7), embora as idades KAr sejam em menor número comparativamente aos demais domínios. As idades em anfibólios atingem valores de até $1,18 \mathrm{Ga}$, ao passo que as biotitas revelam-se totalmente rejuvenescidas $(\sim 540$ Ma). Isto sugere para a evolução térmica desta região um vínculo de caráter reflexo com os eventos metamórficos da Faixa Rio Preto. Esta hipótese é alicerçada também pelas idades $\mathrm{K}$-Ar nas unidades metassedimentares da faixa, que se concentram entre $600-540 \mathrm{Ma}$ (micas), mas sendo ali registrada uma idade em anfibólio de $850 \mathrm{Ma}$ (Silva, 1987; Mascarenhas \& Garcia, 1989). Em adição, o padrão geocronológico da Faixa Rio Preto parece ter relação com os processos de rejuvenescimento isotópico $\mathrm{K}$-Ar constatados na provincia $\mathrm{Pa}$ ramirim, conforme anteriormente exposto.

\section{CONSIDERACŌES FINAIS}

De maneira geral, pode-se afirmar que o quadro heterogêneo exibido pelas idades $\mathrm{K}$ - $\mathrm{Ar}$ nos diferentes setores do CSF vincula-se à sua evolução crustal policíclica (Arqueano e Proterozóico), estabelecida com base em evidências isotópicas de $\mathrm{Sr}, \mathrm{Pb}$, Nd e idades absolutas U-Pb (e.g., Cordani et al,, 1992; Machado \& Carneiro, 1992; Teixeira, 1992, 1993; Nutman \& Cordani, 1993). Além disso, este quadro acha-se influenciado pela complexa história tectonotermal subseqüente, associada ao próprio contexto tectônico do Continente Gondwana Ocidental durante o Neopro- terozóico (e.g., Brito Neves \& Cordani, 1991).

Grande parte do acervo K-Ar, característico tanto para idades em micas como anfibólios, inclusive para rochas pertencentes ao substrato das provincias arqueanas, concentra-se no tempo entre 2,1-1,8 Ga. Por exemplo, tal padrão é observado notadamente nos setores setentrional-leste (regiôes de Campo Formoso-Serrinha e Jequié; Figs. 3 e 4) e meridional-oeste cratônicos (região Oliveira-Divinópolis-Formiga-Lavras; Fig. 5).

Este comportamento coerente das idades K-Ar em extensas áreas do CSF é interpretado como reflexo do progressivo soerguimento da massa continental, em resposta ao término dos processos tectonomagmáticos do Ciclo Transamazônico. Em termos geodinâmicos, este quadro é coerente com a evolução no Paleoproterozóico de três cinturões móveis (ver seções anteriores), os quais se instalaram marginalmente aos blocos continentais primitivos, aglutinados há cerca de 2,8-2,6 Ga. Por outro lado, o soerguimento generalizado do substrato destes cinturôes móveis durante as etapas de estabilização tectônica (detectado pelas idades aparentes), aliado aos trends submeridianos e à atual distribuição geográfica dos mesmos, sugere que a porção mais interna do proto-CSF (hoje recoberta pela cobertura plataformal) ter-se-ia mantido relativamente mais estável por ocasião dos processos tectonomagmáticos do Paleoproterozóico (e.g., Cordani \& Brito Neves, 1982). Esta hipótese é corroborada por dados isotópicos de $\mathrm{Nd}, \mathrm{Pb}$ e $\mathrm{Sr}$ em rochas da provincia arqueana da porção setentrional do CSF (e.g., Teixeira, 1993), bem como, indiretamente, através de granitos que intrudiram o Sistema Jacobina no Ciclo Transamazônico, cujas evidências isotópicas de $\mathrm{Sr}$ (altas razōes iniciais) e Nd (valores negativos de $\varepsilon_{\mathrm{Na}}$ ) são indicativas de uma origem a 
partir do retrabalhamento diferencial de crosta arqueana (Sabaté et al., 1990).

É interessante acrescentar que a conotação arqueana deste dominio central acha-se também surpreendentemente registrada por escassas idades $\mathrm{K}$ $\mathrm{Ar}$, sempre em anfibólios. Este fato vem demonstrar a elevada temperatura de bloqueio de argônio deste mineral, o que permitiu inibir, em alguns poucos casos, o rejuvenescimento isotópico do mineral por conta dos extensivos processos transamazônicos acima citados. Estes registros acham-se preservados tanto na região norte cratônica (idades de 3,11$2,99 \mathrm{Ga}, 2,78 \mathrm{Ga}, 2,40 \mathrm{Ga}$ e $2,21 \mathrm{Ga}$ ) como em seu domínio meridional $(2,56$ $\mathrm{Ga}, 2,39 \mathrm{Ga}$ e 2,26 Ga).

Năo obstante, cabe notar que parte deste núcleo central primitivo da porção setentrional (Fig. 4) mostra idades $\mathrm{K}$-Ar parcialmente rejuvenescidas por processos proterozóicos (1.75-1.10 $\mathrm{Ga}$ ), a exemplo da regiâo do vale do Paramirim. Isto vem caracterizar a maior susceptibilidade do método K-Ar em sofrer rejuvenescimentos comparativamente a outros métodos de datação, como o Rb-Sr em rocha total. Estas idades K-Ar heterogêneas aparecem também nos dominios de transição do antepais com o cinturão marginal (e.g., extremidade meridional do sistema Espinhaço; faixas Araçuai e Rio Preto), conforme anteriormente apresentado, podendo tratar-se, em alguns casos, de idades hibridas, desprovidas de significado geológico.

E interessante constatar que estes domínios geográficos exibem, adicionalmente, padrões $\mathrm{K}-\mathrm{Ar}$ ainda mais jovens (detectados, inclusive, por idades em anfibólios) - 0,80/0,65 Ga; $0,65 / 0,50$ $\mathrm{Ga}$, caracterizando, no geral, um gradativo rejuvenescimento do centro para as extremidades da área investigada. Isto sugere a associação desses rejuvenescimentos com os processos metamórficos brasilianos, cujo padrão de resfriamento
K-Ar no interior das faixas móveis é comparável ou pouco mais jovem (Figs. 4,5 e 6 ).

Por outro lado, os setores marginais do CSF exibem histórias térmicas distintas quando analisados de modo conjunto. Os bruscos contrastes nos padrões de resfriamento $\mathrm{K}-\mathrm{Ar}$, observados para os setores NE, NW e SW, sinalizam a ambiência tectônica relativamente "fria" dos setores, sem o envolvimento da infraestrutura do antepais na deformação e metamorfísmo associados aos processos colisionais das faixas Sergipana, Rio Preto e Canastra. Já nas margens sudeste e leste do CSF, onde o padrão das idades K-Ar é muito semelhante aos das faixas neoproterozóicas adjacentes, os episódios tectônicos brasilianos chegaram a envolver as rochas da infraestrutura das bordas do antepais, conforme também corroborado pelo arcabouço estrutural mostrando a reativação das estruturas desses setores (e.g., Marshak \& Alkmim, 1989).

Em especial, a constatação de um padrâo brasiliano de rejuvenescimento das idades K-Ar na província (mesoproterozóica) Paramirim vem demonstrar o soerguimento deste setor durante o Neoproterozóico, processo este que foi acompanhado por deformações e grandes cisalhamentos, tanto na infraestrutura como no Supergrupo Espinhaço e setores do Grupo Chapada Diamantina, conforme observado por Dominguez (1993) e Trompette et al. (1993). Aparentemente, estas feições de reativação tectônica, levando à inversão do rift Espinhaço, foram induzidas por mecanismos focados nas faixas colisionais Araçuai e Rio Preto, conforme proposto por Alkmim et al. (1993), com base em inferências de cunho estrutural.

É importante ressaltar que a reativação brasiliana não foi acompanhada por plutonismo cálcio-alcalino no interior da provincia Paramirim, o que implica inferir que nenhum processo tectono- 
magmático motriz ali se instalou durante - Neoproterozóico. Portanto, o CSF comportou-se, do ponto de vista geocronológico e geodinâmico, como uma entidade fisica única em relação à evolução tectônica neoproterozóica às suas margens, o que corrobora a recente proposição de Alkmim et al. (1993).

De todo modo, torna-se evidente que o sistema $\mathrm{K}-\mathrm{Ar}$ é demasiadamente sensivel para a definição da paleogeografia dos limites físicos do CSF em relação às faixas marginais brasilianas, pois essas datações respondem diferencialmente ao metamorfismo e deformação, bem como em relação aos níveis crustais associados a essas colisōes. Esta é uma das causas da dificuldade de se obter consenso acerca do principal critério aplicável na delimitação do CSF, tanto em face da resposta diferencial dos diferentes métodos geocronológicos, como também pela interação das interpretações geocronológicas com as obtidas a partir de outras ferramentas de estudo, como a estrutural e a geofísica.

\section{AGRADECIMENTOS}

Os autores agradecem ao CPGeo e ao Centro de Processamento de dados do IG-USP pelo acesso aos dados radiométricos e sua digitalização. Agradecemos também ao CNPq pelo apoio concedido ao bolsista IC.

\section{REFERÊNCIAS BIBLIOGRÁFICAS}

ALMEIDA, F.F.M. (1977) O Cráton do São Francisco. Revista Brasileira de Geociências, v. 7, n. 4, p. 349-364. ALKMIM, F. F.; BRITO NEVES, B.B; ALVES, J.A.C. (1993) Arcabouço Tectônico do Cráton do São Francisco - uma revisão. In: DOMINGUEZ, J.M.L.; MISI, A. (eds.). O Cráton do São Francisco: trabalhos apresentados na reunião preparatória do II Simpósio sobre o Cráton do
São Francisco. Salvador, SBG, p.4562.

ALKMIM, F.F.; CHEMALE Jr., F.; ENDO, I. (no prelo) A deformação das coberturas proterozóicas do Cráton do São Francisco e seu significado tectônico. Revista Brasileira de Geociências.

BABINSKI, M.; BRITO NEVES, B. B.; MACHADO, N.; NOCE, C.M.; UHLEIN, A; VAN SCHMUS, W. R. (1994) Problemas da metodologia U-Pb em zircões de vulcânicas continentais - Caso do Grupo Rio dos Remédios, Supergrupo Espinhaço, no Estado da Bahia. In: CONGRESSO BRASILEIRO DE GEOLOGIA, 38 ., Camboriú, 1994. Boletim de Resumos Expandidos. Camboriú, SBG. v. 2 , p. 409-411.

BASTOS LEAL, L.R.; TEIXEIRA, W; BELLIENI, G.; PETRINI, R;; PICCIRILLO, E.M. (no prelo) Geocronologia e inferências isotópi-ca de $\mathrm{Sr}$ e Nd nos diques máficos do $\mathrm{Cu}$ raçá, Cráton do São Francisco (Brasil): registro de um evento distensivo neoproterozóico associado à evolução da faixa colisional Sergipana. Geochimica Brasiliensis.

BASTOS LEAL, L.R; TEIXEIRA, W: PICCIRILLO, E.M; MENEZES LEAL, A.B.; GIRARDI, V.A.V. (1994) Geocronologia $\mathrm{Rb} / \mathrm{Sr}$ e K/Ar do enxame de diques máficos de Uauá, Bahia (Brasil). Geochimica Brasiliensis, v. 8, n. 1, p.99-114.

BRITO NEVES, B.B.; CORDANI, U.G. (1978) Geocronologia do Precambriano, In: Texto explicativo para o mapa do Estado da Bahia, escala 1/1.000.000. SME/Ba, p.3249.

BRITO NEVES, B.B; CORDANI, U.G. (1991) Tectonic evolution of South Amercia during the Late Proterozoic. Precambrian Research, v. $53, \mathrm{n} .1-2$, p. $23-40$.

BRITO NEVES, B.B.; CORDANI, 
U.G.; TORQUATO, J.R.F. (1980) Evolução geocronológica do précambriano do Estado da Bahia. In: INDA, H.A.V; DUARTE, F.B. (eds.) Geologia e recursos minerais do Estado da Bahia: textos básicos, Salvador, SME-BA/CPM. v. 3, p.1101.

BRITO NEVES, B.B.; KAWASHITA, K; DELHAL, J. (1979) Evolução geocronológica do Pré-Cambriano da cordilheira do Espinhaço; dados novos e integração. Revista Brasileira de Geociências, v. 9 , n. 1, p.71-85.

BRITO NEVES, B.B.; TEIXEIRA, W.; TASSINARI, C.C.G.; KAWASHITA, K. (1990) Contribution to the geochronological subdivision of the Precambrian of South America. Revista Brasileira de Geociências, v. 20 , n. $1-4$, p. 267-276.

CARNEIRO, M.A. (1992) O complexo metamórfico Bonfim Setentrional: evoluçâo geológica de um segmento arqueano de crosta continental. São Paulo, 232p. (Tese - Doutorado) - Instituto de Geociências, Universidade de São Paulo.

CHEMALE Jr, F.; ROSIĖRE, C.A.; ENDO, I. (1991) Evolução tectônica do Quadrilátero Ferrifero, Minas Gerais - um modelo. Pesquisas. Porto Alegre, v. 18, n. 2, p.104-127.

CHEMALE Jr., F.; ALKMIM, F.F.; ENDO, L. (no prelo) Late Proterozoic tectonism in the interior of the São Francisco Craton. Ann. Gondwana Symposium, 5.

CORDANI, U.G. (1973) Evolução geológica pré-Cambriana da faixa costeira do Brasil entre Salvador e Vitória. São Paulo, 98p. (Tese - Doutorado) - Instituto de Geociências, Universidade de São Paulo.

CORDANI, U.G.; BERNAT, M.; TEIXEIRA, W; KAWASHITA, K. (1974) Idades radiométricas das rochas alcalinas do Sul da Bahia. In: CONGRESSO BRASILEIRO DE
GEOLOGIA, 28., Porto Alegre, 1974. Anais, Porto Alegre, SBG. v. 6, p. 253-259.

CORDANI, U.G.; BRITO NEVES, B.B. (1982) The geologic evolution of South America during the Archean and Early Proterozoic. Revista Brasileira de Geociências, v. $12, n$. 1-3, p. 78-88.

CORDANI, U.G.; KAWASHITA, K.; SATO, K; IYER, S.S; TAYLOR, P.N. (1992) Pb-Pb, Rb-Sr and K-Ar systematics of the Lagoa Real Uranium Province (South Central Bahia, Brazil) and the Espinhaço cycle (ca. 1.5-1.0 Ga). Journal of South American Earth Sciences, v. 5 , n. 1 , p.33-36.

CORDANI, U.G.; SATO, K; MARINHO, M.M. (1985). The geologic evolution of the ancient granitegreenstone terrane of central-southern Bahia, Brazil. Precambrian Research, v. 27 , n. 1-3, p. 187-213.

DALRYMPLE, G.B.; LANPHERE, M.A. (1969) Potassium-argon dating. San Francisco, Freeman, $258 \mathrm{p}$.

DOMINGUEZ, J.M.L. (1993) As coberturas do Cráton do São Francisco: uma abordagem do ponto de vista da análise de dados. In: DOMINGUEZ, J.M.L.; MISI, A. (eds.), O Cráton do São Francisco: trabalhos apresentados na reunião preparatória do II Simpósio sobre o Cráton do São Francisco. Salvador, SBG. p.137-159.

FAURE, G. (1986) Principles of Isotope Geology. 2. ed., New York, John Wiley. 589p.

FIGUEIREDO, M.C.H. (1989) Geochemical evolution of eastern Bahia, Brazil: a probable Early Proterozoic subduction-related magmatic arc. Journal of South American Earth Sciences, v. 2, n.2, p. 131-145.

HANES, J.A. (1991) K-Ar and ${ }^{40} \mathrm{Ar}-$ ${ }^{39} \mathrm{Ar}$ geochronology: methods and 
applications. In: HEAMAN, L.; LUDDEN, J.N. (eds.) Aplications of radiogenic isotope systems to problems in geology. Toronto, Mineralogical Association of Canada, p.27-57 (short course handbook, v. 19).

HARRISON, T.M. (1981) Diffusion of ${ }^{40} \mathrm{Ar}$ in hornblende. Contributions Mineralogy Petrology, v.78, n. 3, p. 324-331.

HARRISON, T.M.; DUNCAN, I.; MCDOUGALL, I. (1985) Diffusion of ${ }^{40} \mathrm{Ar}$ in biotite: temperature, pressure and compositional effects. Geochimica et Cosmochimica Acta, v. 49, n. 11, p. 2461-2468.

HASUI, Y; TASSINARI, C.C.G.; SIGA Jr., O., TEIXEIRA, W.; ALMEIDA, F.F.M.; KAWASHITA, K. (1980) Datações Rb/Sr e K/Ar do Centro Norte do Brasil e seu significado geológico-geotectônico. In CONGRESSO BRASILEIRO DE GEOLOGIA, 31., Camburiú, 1980. Anais, Porto Alegre, SBG. v. 5, p. 2659-2676.

HEAMAN, L. (1991) U-Pb dating of giant radiating dyke swarms: potencial for global correlation of mafic magmatic events. In: INTERNATIONAL SYMPOSIUM ON MAFIC DYKES. São Paulo, 1991. Abstracts, São Paulo, SBGq. p.7-9.

HERZ, N. (1970) Gneissic and Igneous Rocks of the Quadrilatero Ferrifero, Minas Gerais, Brazil. U.S. Geological Survey Professional Paper, $\mathrm{n}$. 641 B, p. 1-58.

KARMANN, I. (1987) O Grupo Rio Pardo (Proterozóico Médio a Superior): uma cobertura paraplataformal da margem sudeste do Cráton do São Francisco. São Paulo, 129p. (Dissertação - Mestrado) - Instituto de Geociências, Universidade de São Paulo.

LIMA, M.I.C.; FONSECA, E.G.; OLIVEIRA, E.P.; GHIGNONE, J.I.;
ROCHA, R.M; CARMO, U.F; SILVA, J.M.R.; SIGA Jr., O. (1981) Geologia. In: PROJETO RADAMBRASIL. Folha SD-24 Salvador. Geologia, Geomorfologia, Pedologia, Vegetação, Uso potencial da terra. Rio de Janeiro, p.25-192 (Levantamento de Recursos Naturais, 24).

LITWINSKI, N. (1986) A evolução tectonotermal da regiāo nordeste de Minas Gerais e sul da Bahia. São Paulo, 207p. (Tese - Doutorado) - Instituto de Geociências, Universidade de São Paulo.

MACHADO, N; CARNEIRO, M.A. (1992) A major Archean tectonothermal event in the São Francisco shield, Brazil: U-Pb evidence from the Quadrilátero Ferrifero, Minas Gerais. Canadian Journal of Earth Sciences, v. 29, n. 11, p.2341-2346.

MACHADO, N:; SCHRANK, A.; ABREU, F.R.; KNAUER, L.G.; ABREU, P.A.A. (1989) Resultados preliminares da geocronologia $\mathrm{U} / \mathrm{Pb}$ na Serra do Espinhaço Meridional. In: SIMPÓSIO DE GEOLOGIA NÚCLEO MINAS GERAIS, 5./ SIMPÓSIO DE GEOLOGIA NÚCLEO BRASÍLIA, 1., Belo Horizonte, 1989. Anais, Belo Horizonte, SBG. Núcleo Minas Gerais. p.171174.

MACHADO FILHO, L.; RIBEIRO, M.W.; GONZALEZ, S.R.; SCHENINI, C.A.; PALMEIRA, R.C.B.; GATTO, C.M.P.P.; SANTOS NETO, A; SOUZA Jr., J.J.; PIRES, J.L; TEIXEIRA, W.; MARTINS, V.M.F; CASTRO, H.E.F.; HERTER A.M. (1984) Geologia. In: PROJETO RADAMBRASIL. Folhas SF-23/24 Rio de Janeiro/Vitória. Rio de Janeiro, MME/SG. p.27-304. (Levantamento de Recursos Naturais, 32).

MARINHO, M.M; BARBOSA, J.S.F. (1993) O embasamento do Cráton do São Francisco no sudeste da Bahia: 
revisão geocronológica. In: SIMPÓSIO SOBRE O CRATON DO SÃO FRANCISCO, 2., Salvador, 1993. Anais, Salvador, SBG, p.12-16.

MARSHAK, S.; ALKMIM, F.F; JORDT-EVANGELISTA, H. (1992) Proterozoic crustal extension and the generation of dome-and-keel structure in an Archaean granite-greenstone terrane. Nature, v. 357 , n. 6378, p.491-493.

MASCARENHAS, J.F; GARCIA, T.W. (1989) Mapa geocronológico do Estado da Bahia: escala 1:1.000.000. Texto explicativo. Salvador: SME/SGM. 188 p.

NUTMAN, A.P.; CORDANI, U.G. (1993) SHRIMP U/Pb zircon geochronology of Archean gnaisses, São Francisco Cráton, Bahia. Precambrian Research, v. 63, n. 3-4, p.179188.

PEDROSA SOARES, A.C.; GROSSI SAD, J.H; VIDAL, P.H. (1993) Evidences of a constructive margin in the Sanfranciscan plate (Araçuai belt, MG): ageochemical evaluation of metabasic rocks. In: SIMPÓSIO SOBRE O CRÁTON DO SÃO FRANCISCO, 2., Salvador, 1993. Anais, Salvador, SBG, p.131-133.

PEDROSA SOARES, A.C.; NOCE, C.M.; VIDAL, P.H.; MONTEIRO, R.L.B.P.; LEONARDOS, O.H. (1992) Toward a new tectonic model for the Late Proterozoic Araçuai: (SE Brazil) - West Congolian (SW Africa) Belt. Journal of South American Earth Sciences, v. 6, n. 1-2, p. 33-47.

PIMENTEL, M.M:; MACHADO, N: LOBATO, L.M. (1994) Geocronologia U-Pb de rochas graniticas e gnáissicas da região de Lagoa Real, Bahia, e implicações para a idade da mineralização de urânio. In: CONGRESSO BRASILEIRO DE GEOLOGIA, 38., São Paulo, 1994. Anais, São Paulo, SBG, São Paulo.
Boletim de Resumos Expandidos, v. 2, p. 389-390.

RENNE, P.R.; ONSTOTT, T.C.; D'AGRELLA FILHO, M.S.; PACCA, I.G.; TEIXEIRA, W. (1990) ${ }^{40} \mathrm{Ar}-{ }^{39} \mathrm{Ar}$ dating of $1.0-1.1 \mathrm{Ga}$ magnetizations form the São Francisco and Kalahari Cratons: tectonic implications for Pan African and Brasiliano mobile belts. Earth and Planetary Science Letters, v. 101, n. 2-4, p. 349-366.

SÁ, J.H. (1977) Pegmatitos litiniferos da regiẫo de Itinga-Araçuaí, Minas Gerais. São Paulo, 112p. (Tese Doutorado) - Instituto de Geociências, Universidade de São Paulo.

SABATÉ, P.; MARINHO, M.M; VIDAL, P.; CAEN-VACHETTE, M. (1990) The 2-Ga peraluminous magmatism of the Jacobina - Contendas Mirante belts (Bahia, Brazil): geologic and isotopic constraints on the sources. Chemical Geology, v. 83 , n. 3-4, p.325-338.

SATO, K (1986) Síntese geocronológica do Estado da Bahia e evolução crustal com base no diagrama de evolucão do $\mathrm{Sr}$ e razóes iniciais $\mathrm{Sr}^{87} / \mathrm{Sr}^{86}$. São Paulo, $124 \mathrm{p}$. (Dissertação - Mestrado) - Instituto de Geociências, Universidade de São Paulo.

SCHOBBENHAUS, C.; ALMEIDA CAMPOS, D.; DERZE, G.R.; ASMUS, H.E. (1984) Geologia do Brasil: texto explicativo do mapa geológico do Brasil e da área oceânica adjacente incluindo depósitos minerais, escala 1: 2.500 .000 . Brasilia, DNPM. 501p.

SCHOBBENHAUS, C.; HOPPE, A.; LORK, A; BAUMANN, A. (1994) Idade $\mathrm{U} / \mathrm{Pb}$ do vulcanismo Rio dos Remédios, Chapada Diamantina, Bahia. In: CONGRESSO BRASILEIRO DE GEOLOGIA, 38., Camboriú, 1994. Boletim de Resumos Expandidos, Camboriú, SBG. v. 2, p.395- 
396.

SIGA Jr., O. (1986) A evoluçäo geotectônica da porção nordeste de Minas Gerais, com base em interpretaçōes geocronológicas. São Paulo, 140p. (Dissertação - Mestrado) - Instituto de Geociências, Universidade de São Paulo.

SIGA Jr., O.; CORDANI, U.G.; BASEI, M.A.S.; TEIXEIRA, W.; KAWASHITA, K; VAN SCHMUS, $\mathbf{R}$. (1987) Contribuição ao estudo geológico-geocronológico da porção nordeste de Minas Gerais. In: SIMPÓSIO DE GEOLOGIA DE MINAS GERAIS, 4., Belo Horizonte, 1987. Anais, Belo Horizonte, SBG Núcleo Minas Gerais. p.29-44.

SILVA, M.E. (1987) O sistema de dobramentos Rio Preto e suas relações com o Cráton do São Francisco. São Paulo, 141p. (Tese Doutoramento) - Instituto de Geociências, Universidade de São Paulo.

SILVA, ME; TROMPETTE, R; KARMANN, I.; UHLEIN, A. (1993) A tectônica do Grupo Rio Pardo no contexto cinemático do Cráton do São Francisco. In: SIMPÓSIO SOBRE O CRÁTON DO SÃO FRANCISCO, 2., Salvador, 1993. Anais, Salvador, SBG, p.249-251.

SLETTEN, V.M. (1989) ${ }^{40}$ Ar- ${ }^{39}$ Ar thermochronometry of the JequicComplex, state of Bahia, Brazil. Princeton, 21p. (Junior Paper) - Department of Geological and Geophysical Sciences. Princeton University.

STOCKWELL, C.H. (1982), Proposals for time classification and correlation of Precambrian rocks and events in Canada and adjacent areas of the Canadian Shield. Part 1. Geological Survey Canada Paper, n. 80-19, $135 p$.

TAVORA, F.J; CORDANI, U.G.; KAWASHITA, K. (1967) Determi- nações de idade $\mathrm{K}-\mathrm{Ar}$ em rochas da região central da Bahia. In: CONGRESSO BRASILEIRO DE GEOLOGIA, 21, Curitiba, 1967. Anais. Curitiba, SBG, p.234-244.

TEIXEIRA, W. (1985) A evolução geotectônica da porção meridional do Cráton do Sẩo Francisco, com base em interpretaçōes geocronológicas. São Paulo, 207p. (Tese Doutorado) - Instituto de Geociências, Universidade de São Paulo.

TEIXEIRA, W. (1992) Contribuição ao conhecimento geocronológico do Cráton do São Francisco: avaliação de dados isotópicos em rochas igneas e metamórficas implicaçōes na evoluçâo crustal pré-cambriana. São Paulo, 172p. (Tese Livre-Docência) - Instituto de Geociências, Universidade de São Paulo.

TELXEIRA, W. (1993) Avaliação do acervo de dados geocronológicos e isotópicos do Cráton do São Francisco - implicações tectônicas. In: DOMINGUEZ, J.M.L.; MISI, A. (eds.) $O$ Cráton do São Francisco: trabalhos apresentados na reunião preparatória do II Simpósio sobre o Cráton do São Francisco. Salvador, SBG. p.11-34.

TEIXEIRA, W.; AKIMOTO, H.; SIGA Jr., O.; SATO, K. (1989) A evolução geocronológica dos terrenos granítico-gnáissico-migmatíticos ao sul da faixa Canastra, sudoeste de Minas Gerais. In: SIMPÓSIO DE GEOLOGIA, NÚCLEO MINAS GERAIS, 5./ SIMPÓSIO DE GEOLOGIA, 1., Belo Horizonte, 1989. Anais. Belo Horizonte, SBG Núcleo Minas Gerais, Boletim n. 10, p. 243-246.

TELXEIRA, W.; DOSSIN, I.A.; DOSSIN, T.M.; SALVADOR, E.D; SIGA Jr., O. (1990) Interpretação do contexto geotectônico do embasamento na borda leste do sistema Es- 
pinhaço, região de Guanhães e Gouveia, MG, com base numa integração do seu conjunto geocronológico U$\mathrm{Pb}, \mathrm{Rb}-\mathrm{Sr}$ e K-Ar. In: CONGRESSO BRASILEIRO DE GEOLOGIA, 36., Natal, 1990. Anais, Natal, SBG Núcleo Nordeste. v. 6, p. 2711-2722.

TEIXEIRA, W; CARNEIRO, M.A.; NOCE, C.M; MACHADO, N.; SATO, K; TAYLOR, P.N. (no prelo) $\mathrm{Pb}, \mathrm{Sr}$ and $\mathrm{Nd}$ isotope constraints on the Archean evolution of gneissicgranitoid complexes in the Southern São Francisco Craton, Brazil. Precambrian Research, v. 78.

TEIXEIRA, W.; FIGUEIREDO, M.C. H. (1991) An outline of Early Proterozoic crustal evolution in the São Francisco Cráton: a review. Precambrian Research, v. 53, n. 1-2, p.122.

TEIXEIRA, W; JORDT EVANGELISTA, $\mathrm{H}$; KAWASHITA, K ; TAYLOR, P. N. (1987) Complexo granulítico de Acaiaca, MG: idade, petrogênese e implicações tectônicas. In: SIMPÓSIO DE GEOLOGIA DE MINAS GERAIS, Belo Horizonte, SBG. Anais. Belo Horizonte, SBG. Núcleo Minas Gerais. p.58-71.

TEIXEIRA, W.; SILVA, F.C. (1993) A evolução tectonotermal proterozóica do Craton do São Francisco, com base em interpretações geocronológicas $\mathrm{K}-\mathrm{Ar}$. In: SIMPÓSIO SOBRE O CRÁTON DO SÃO FRANCISCO, 2., Salvador, 1993. Anais, Salvador, SBG. p. 18-20.

TROMPETTE, R. (1989) Ensialic evolution of the centrifugal Araçuai -
West Congo (Zaire), role of Middle Proterozoic fracturation. In: INTERNATIONAL GEOLOGICAL CONGRESS, 28., Washington, 1989. Abstracts, Washington, v. 3, p. 255.

TROMPETTE, R.R. (1994) Geology of estern Gondwana (2000 - $500 \mathrm{Ma})$ : Pan-African-Brasiliano Aggregation of South America and Africa. (translated by A. V. Carozzi). Rotterdam, Balkema, $350 \mathrm{p}$.

TROMPETTE, R.R; UHLEIN, A.; SILVA, M.E; KARMANN, I. (1993) O Cráton brasiliano do São Francisco - Uma revisão. Revista Brasileira de Geociências, v. 22, n. 4, p. 481-486.

TURPIN, L.; MARUEJOL, P.; CU$\mathrm{NEY}, \mathrm{M}$. (1988) U-Pb, Rb-Sr and Sm-Nd chronology of granitic basement, hidrothermal albitites and uranium mineralization (Lagoa Real, South - Bahia, Brazil). Contributions Mineralogy Petrology, v.98 n. 2 , p. 139-147.

VALERIANO, C.M. (1992) Evoluçấo tectônica da extremidade meridional da Faixa Brasilia, regiăo da represa de Furnas, sudoeste de $\mathrm{Mi}$ nas Gerais. São Paulo, 192p.(Tese Doutorado) - Instituto de Geociências, Universidade de São Paulo.

WILSON, N. (1987) Combined Sm$\mathrm{Nd}, \mathbf{P b}-\mathbf{P b}$ and $\mathbf{R b}-\mathrm{Sr}$ geochronol. ogy and isotope geochemistry polymetamorphic Precamb terrains: examples from $B$ ahlas, Brazil and Channel, Island, U.K. Oxford. Oxford, s.p. (Dissertação Mestrado) - Universidade de Oxford.

W.Teixeira - Instituto de Geociências, Universidade de São Paulo, Caixa Postal 11.348, CEP 05422-970, São Paulo, SP, Brasil. 